\title{
Restriction endonuclease analysis using Hhal and Hpall to discriminate among group B Pasteurella multocida associated with haemorrhagic septicaemia
}

\author{
RICHARD B. RIMLER
}

Avian and Swine Respiratory Diseases Research Unit, USDA/Agricultural Research Service/National Animal Disease Center, PO Box 70, Ames, IA 50010, USA

\begin{abstract}
The purpose of this study was to improve and standardise restriction endonuclease analysis (REA) for discriminating isolates of serogroup B Pasteurella multocida associated with haemorrhagic septicaemia in wild and domestic animals and to create a reference database that can be used for epidemiological studies. Two techniques for extraction and isolation of chromosomal DNA were compared, a DNAzol ${ }^{\circledR}$ method and an enzymic lysis followed by a two-phase partition method. No differences were observed between DNA fingerprint profiles with either technique; however, the former technique was faster and easier to perform. P. multocida isolated from different animals in different countries representing serotypes $B: 2, B: 3, B: 3,4$ and $B: 4$ were subjected to $\mathrm{REA}$ with $\mathrm{H}$ hal and $\mathrm{H}$ pall endonucleases. Forty-eight fingerprint profiles were distinguished among 222 isolates when only $\mathrm{H}$ hal was used. By combining the data from REA with Hhal and Hpall used separately, 88 different groups could be distinguished among the same isolates. Following digestion with $\mathrm{H}$ hal and electrophoresis, the DNA of all serotype B:2 isolates produced fingerprint profiles characterised by two trailing bands at $\sim 8.4-7.1 \mathrm{~kb}$ which have not been observed in any other serotypes of $P$. multocida. Passage of three serotype B:2 isolates on laboratory media or two serotype $B: 2$ isolates through mice did not result in a change of DNA fingerprint profile detectable by REA. The findings with 59 isolates from Sri Lanka showed that REA was highly discriminative in determining the genetic diversity of serotype B:2 P. multocida in an area where haemorrhagic septicaemia is endemic.
\end{abstract}

\section{Introduction}

Haemorrhagic septicaemia (HS) is an acute and often fatal disease principally occurring in cattle and water buffalo, but occasionally other domesticated and wild mammals can be affected [1,2]. The disease is particularly endemic in Asia and Africa, but outbreaks have occurred in Europe and North A merica. Pasteurella multocida serotypes $B: 2$ and $E: 2$ are the principal cause of HS. However, the E:2 serotype has been isolated only from animals in A frica. In recent years, serotypes $B: 3, B: 4$ and $B: 3,4$ have been implicated as a cause of HS in cattle and wild ruminants such as deer, elk, and bison $[3,4,5,6,7, R$. B. Rimler unpublished

Received 16 March 1999; revised manuscript received 12 June 1999; accepted 30 June 1999.

Corresponding author: Dr R. B. Rimler (e-mail: rrimler@ nadc.ars.usda.gov). observations]. The clinical signs and lesions in ruminants such as cattle, bison and deer caused by serotypes $B: 3, B: 4$, and $B: 3,4$ may appear similar, if not indistinguishable, to those seen in water buffalo and cattle caused by serotypes $B: 2$ and E:2. Although most isolations of serogroup $B$. multocida (other than serotype $B: 2$ ) have been made in North America, isolations have been made occasionally from cattle in A ustralia [8] and fallow deer in Denmark [3] and the UK [5].

Environmental and other stresses that predispose domesticated and wild ruminants to outbreaks of HS are often similar. A necdotal information suggests that selenium deficiency may have precipitated some outbreaks of HS caused by serotype B:3,4. Pasteurella multocida does not live freely in the environment, and there are no reports describing serogroup $B$ or $E$ pasteurellas being isolated from free-flying birds, 
rodents or man, suggesting that they are not intermediate hosts to the bacteria. Carrier animals are the reservoir for pasteurellas causing HS [1,2], and the pharyngeal tonsils have been shown to be sites of carriage in healthy animals [1, 2]. In HS endemic areas, the number of carrier animals in buffalo and cattle herds may range from $<1 \%$ to $>40 \%$ [1]. Presumably, a similar situation also occurs in wild ruminant herds. It is not known whether diverse strains of the same serotype may be associated with an outbreak or occur in a single carrier animal. Also, it is largely unknown whether more than one strain of a particular HS serotype may occur within a specific endemic area.

Serogroups B and E of P. multocida are distinguished by indirect haemagglutination tests and by their inability to be affected by certain mucopolysaccharidases [9]. Somatic serotypes are distinguished by gel diffusion precipitin tests (GDPT) [10]. Of the serogroup $B$ strains, only the $B: 2$ serotype produces hyaluronidase and chondroitinase [11]. Although serological and conventional biochemical tests are still useful for disease diagnosis and designing vaccination programmes, they are limited in scope for epidemiological purposes, because they cannot differentiate isolates within a particular serotype.

Within the last decade, new and more powerful technologies have become available to discriminate among isolates of P. multocida. A mong these technologies is restriction endonuclease analysis (REA), a technique capable of recognising differences in bacteria within the same serotype [12]. The objectives of this study were to improve and standardise REA for discriminating isolates of serogroup B P. multocida associated with HS in wild and domestic animals and to create a reference database that can be used for epidemiological studies.

\section{M aterials and methods}

\section{Bacteria}

A total of 222 isolates of serogroup B P. multocida was used (Table 1). The isolates were from different mammalian species in different countries, except for one isolate from a chicken. The mammalian isolates originated from cases of HS or from carrier animals in areas where HS had occurred, except for one serotype $B: 3,4$ strain isolated from an ox in Australia. Most isolates were submitted to the National A nimal Disease Center for serotyping, and clinical case information (other than animal host of origin) often was not provided. The majority of the isolates were obtained from Sri Lanka and India, and most of those isolates were from cattle, water buffalo and swine. The capsule serogroup of an isolate was determined by indirect haemagglutination tests, and its somatic type was determined by gel diffusion precipitin tests [13]. The ability of an isolate to produce hyaluronidase was tested as described previously [11].

\section{REA}

Bacteria were grown on blood agar medium base (without added blood; Difco) for $18 \mathrm{~h}$ at $37^{\circ} \mathrm{C}$. Cells were suspended in either TE buffer $(0.01 \mathrm{M}$ Tris$0.001 \mathrm{M}$ EDTA, pH 8.0) or saline and adjusted to $65 \% \mathrm{~T}$ at $600 \mathrm{~nm}$ with a $16 \times 150-\mathrm{mm}$ tube in a model 35 spectrophotometer (Perkin-Elmer). A 1.5-ml volume of the adjusted cell suspension was centrifuged to pellet the cells and chromosomal DNA was obtained from TE buffer-suspended bacteria by enzymic lysis followed by a two-phase partition method [12] or from salinesuspended bacteria with a DNA zol ${ }^{\circledR}$ procedure. For the DNAzol ${ }^{\circledR}$ procedure, after centrifugation of the salineadjusted suspension the supernate was discarded and $1 \mathrm{ml}$ of DNAzol $^{\circledR}$ (Life Technologies, Inc., 9800 Medical Center Drive, Rockville, MD, USA) was added to the tube to resuspend and solubilise the pellet. The solution was allowed to stand for $15 \mathrm{~min}$ at room temperature before $500 \mu \mathrm{l}$ of absolute ethanol were added. The contents of the tube were mixed by end-over-end rotation until a cloudy precipitate formed. The tube was centrifuged at $16000 \mathrm{~g}$ for $2 \mathrm{~min}$ and the supernate was discarded. The pellet was washed twice by centrifugation with $800 \mu \mathrm{l}$ of ethanol $95 \%$ and dried with a vacuum concentrator for $30 \mathrm{~min}$.

The DNA extracted by two-phase partition or DNA$\mathrm{zol}^{\circledR}{ }^{\mathbb{R}}$ procedures was digested with $\mathrm{Hhal}$ or $\mathrm{Hpall}$ endonculease (Life Technologies) as recommended by the manufacturer, and submarine electrophoresis in an agarose $0.7 \%$ gel was done as described previously [12]. A Hindlll digest of $\lambda$ phage was used as a standard at three positions on every gel (both sides and middle) so that gels could be normalised and comparisons of fingerprint profiles from different gels could be made with Gelcompar ${ }^{\circledR}$ (Applied Maths, Kortrijk, B elgium) computer software.

A fter electrophoresis, gels were stained with ethidium bromide and band patterns (fingerprint profiles) were viewed and photographed with ultraviolet light. Photographs were scanned with a Hewlett-Packard IIcx flatbed scanner and Deskscan ${ }^{\circledR}$ software (HewlettPackard, Boise, ID, USA) to create a tagged image format file (tif file) for computer analysis. Images of fingerprint profiles were analysed and similarity between all possible pairs of fingerprint profiles within a serotype or between serotypes was calculated by the cluster analysis module of the Gelcompar ${ }^{\mathbb{R}}$ software using the Dice coefficient and a band position tolerance of $0.5 \%$. Dendrograms were derived from a matrix of similarity values by the unweighted pair group method using arithmetic averages. Isolates that had $>97.3 \%$ similarity based upon the data combined from analysis of fingerprint profiles produced by both $\mathrm{Hhal}$ and $\mathrm{H}$ pall were considered identical. 
R esults

\section{Serology and production of hyaluronidase}

One hundred and ninety-two isolates were identified as serotype $B: 2$ and 30 isolates were identified as serotype $B: 3, B: 4$, or $B: 3,4$ (Table 1). None of the serotype $B: 3$, $B: 4$ or $B: 3,4$ isolates produced hyaluronidase, whereas all the serotype $B: 2$ isolates did.

Distinction between DNA fingerprint profiles and isolation of DNA by two-phase partition or DNAzol methods

Distinction between fingerprint profiles following electrophoresis of the endonuclease digests was determined by the number and position of bands in agarose gels. Although the same fingerprint profile of a particular isolate resulted from endonuclease digestion of DNA isolated by either the two-phase partition or the DNAzol method, the latter method was easier and more quickly performed. A fter adjustment of bacterial suspensions, 20 samples could be processed easily and made ready for electrophoresis within $5 \mathrm{~h}$ by the DNAzol method, in comparison with $7 \mathrm{~h}$ by the twophase partition method.

\section{Distinction among serotype $B: 2$ isolates}

For all 192 serotype B:2 isolates, distinction between fingerprint profiles produced by $\mathrm{H}$ hal was determined with bands in the $8.4-3.35 \mathrm{~kb}$ range, and distinction between profiles produced by $\mathrm{H}$ pall was determined with bands in the $28.3-5.25 \mathrm{~kb}$ range. Bands did not

Table 1. Geographic origin and hosts of serotype $B: 2$, $B: 3, B: 3,4$ and $B: 4$ isolates of HS P. multocida

\begin{tabular}{|c|c|c|c|}
\hline Serotype & Origin & Host & $\begin{array}{l}\text { Number of } \\
\text { isolates }\end{array}$ \\
\hline \multirow[t]{15}{*}{$B: 2$} & Bangladesh & Cattle & 1 \\
\hline & Burma & Buffalo & 4 \\
\hline & China & Cattle, yak & 3 \\
\hline & Egypt & Buffalo & 1 \\
\hline & India & $\begin{array}{l}\text { Buffalo, cattle, deer } \\
\text { sheep, swine }\end{array}$ & 63 \\
\hline & Indonesia & Buffalo, cattle & 16 \\
\hline & M alaysia & Buffalo, chicken & 6 \\
\hline & Philippines & Buffalo & 5 \\
\hline & Romania & Buffalo, cattle & 3 \\
\hline & Spain & Deer, sheep & 7 \\
\hline & Sri Lanka & $\begin{array}{l}\text { Buffalo, cattle, } \\
\text { elephant, unknown }\end{array}$ & 66 \\
\hline & Thailand & Buffalo & 3 \\
\hline & USA & Bison, cattle & 6 \\
\hline & Zimbabwe & Cattle & 3 \\
\hline & Unknown & Unknown & 5 \\
\hline \multirow{7}{*}{$\begin{array}{l}B: 3 \\
B: 3,4\end{array}$} & USA & Bison, elk & 4 \\
\hline & A ustralia & Cattle & 1 \\
\hline & Denmark & Deer & 2 \\
\hline & Canada & Cattle & 2 \\
\hline & UK & Deer & 3 \\
\hline & USA & $\begin{array}{l}\text { Bison, cattle, deer, } \\
\text { elk }\end{array}$ & 14 \\
\hline & Unknown & Unknown & 2 \\
\hline \multirow[t]{2}{*}{$B: 4$} & Canada & Bison & 1 \\
\hline & USA & Elk & 1 \\
\hline
\end{tabular}

occur above these ranges, and bands below these ranges were not well separated and defined.

Thirty-two different profiles were distinguished among the 192 serotype $B: 2$ isolates after digestion with $\mathrm{H}$ hal endonuclease. The DNA of five serotype $B: 2 \quad P$. multocida (isolated from buffalo, sheep and deer in India) could not be digested with $\mathrm{Hpa}$ II endonuclease. Forty-two different DNA fingerprint profiles were distinguished among the remaining 187 isolates digested with Hpall. Fig. 1 shows nine of the most frequently observed DNA fingerprint profiles produced by $\mathrm{Hhal}$ and Hpall. Different isolates which had identical profiles with $\mathrm{Hhal}$ endonuclease did not necessarily have identical profiles with $\mathrm{HpalI}$, and vice versa. Therefore, further discrimination among isolates could be made by combining the data from two separate endonuclease treatments.

Isolates with $>97.3 \%$ similarity following both endonuclease treatments were considered identical and assigned the same descriptive identification epithet (DIE) code [12], i.e., B:2/Hhal 0018/Hpalll 0008. Thus, excluding data from the five isolates whose DNA could not be digested with $\mathrm{Hpall}$ endonuclease (DIE code $B: 2 /$ Hhal 0018/Hpall neg), the serotype $B: 2$ isolates were separated into 70 different DIE coded groups. Percentage similarity among the different serotype $B: 2$ isolates (as represented by distinct DIE codes) ranged from 67.1 SD $5.8 \%$ to $97.3 \%$. There was very little evidence of clustering of isolates according to geographic origin. In fact, isolates with the same DIE code could originate from different continents. For example, B:2/H hal 0018/H pall 0020 represented isolates from Malaysia (one isolate), Egypt (one) and Zimbabwe (three) and B:2/Hhal 0020/Hpall 0025 represented isolates from Indonesia (two isolates), Malaysia (five) and Spain (six).

The findings with 59 isolates from animals in Sri Lanka (kindly provided with information on province of origin by $\operatorname{Dr} M$. De Alwis) produced the best example of the discriminative power of REA and the genetic diversity of serotype $B: 2$ in an area where HS is endemic. Buffalo and cattle were the main sources of these isolates, and isolations were made over a period of c. 12 years. With combinations of serology and REA with the two separate endonucleases, the 59 isolates could be assigned to 34 DIE codes. Similarity between non-identical isolates ranged from 83.6 SD $3 \%$ to $97.3 \%$. Fig. 2 shows a map of Sri Lanka $\left(66000 \mathrm{~km}^{2}\right)$ and the number of different DIE codes that could be found among isolates from each of its eight provinces. As an example of serotype $B: 2$ diversity within a specific geographic region, Fig. 3 shows percentage similarity of DIE coded P. multocida in the Northwestern province isolated over a 12-year period; similarity ranged from 87.9 SD $2.6 \%$ to $97.3 \%$. Strains with the same DIE code could originate from different animal species within Sri Lanka and occur in more 


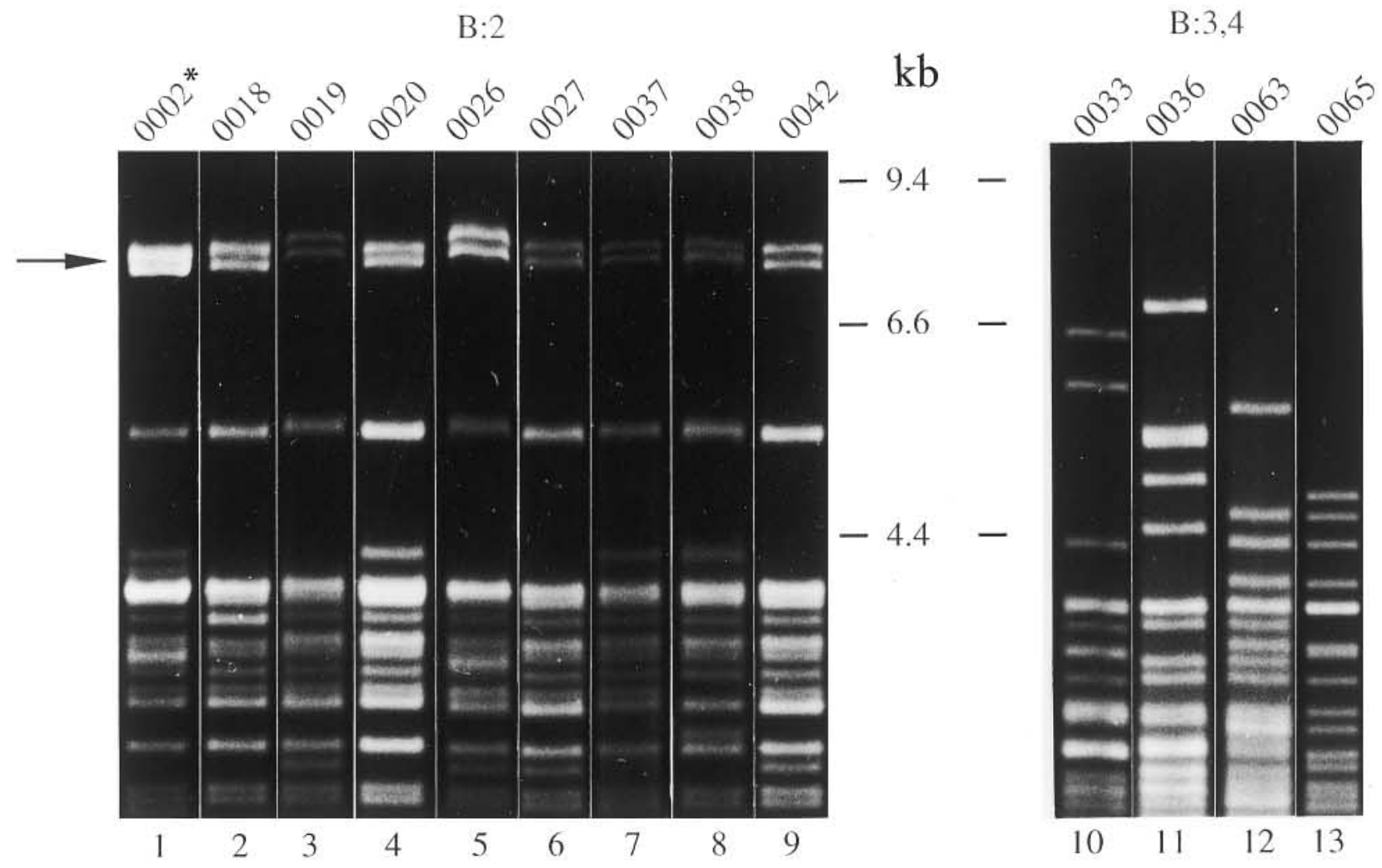

b

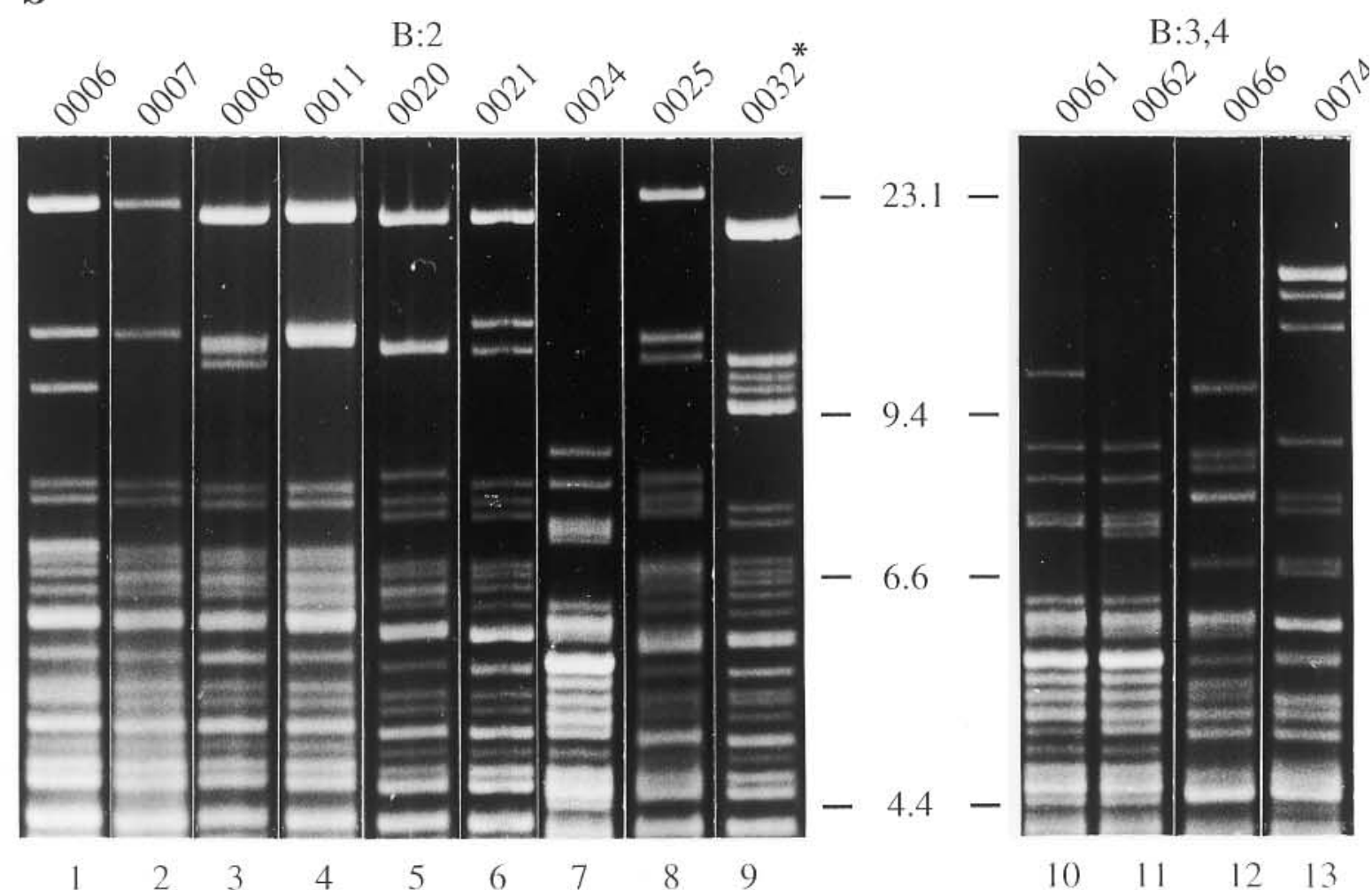

Fig. 1. DNA fingerprint profiles most frequently observed among P. multocida serotypes $B: 2$ and $B: 3,4$ produced by (a) $\mathrm{H}$ hal and (b) $\mathrm{Hpall}$ endonucleases. Each lane shows the representative fingerprint profile for a number of isolates as follows: Iane 1a, 3 isolates; $2 a, 76 ; 3 a, 3 ; 4 a, 19 ; 5 a, 14 ; 6 a, 7 ; 7 a, 6 ; 8 a, 4 ; 9 a, 6 ; 10 a, 5 ; 11 a, 5 ; 12 a, 2 ; 13 a, 3 ; 1 b$, $26 ; 2 b, 44 ; 3 b, 8 ; 4 b, 20 ; 5 b, 6 ; 6 b, 3 ; 7 b, 13 ; 8 b, 14 ; 9 b, 3 ; 10 b, 3 ; 11 b, 2 ; 12 b, 3 ; 13 b, 2$. A rrow shows two trailing bands in the 8.4-7.1-kb range which are characteristic of all serotype $\mathrm{B}: 2$ isolates. *Fingerprint profile of serotype $\mathrm{B}: 2$ type strain $M-1404$. 


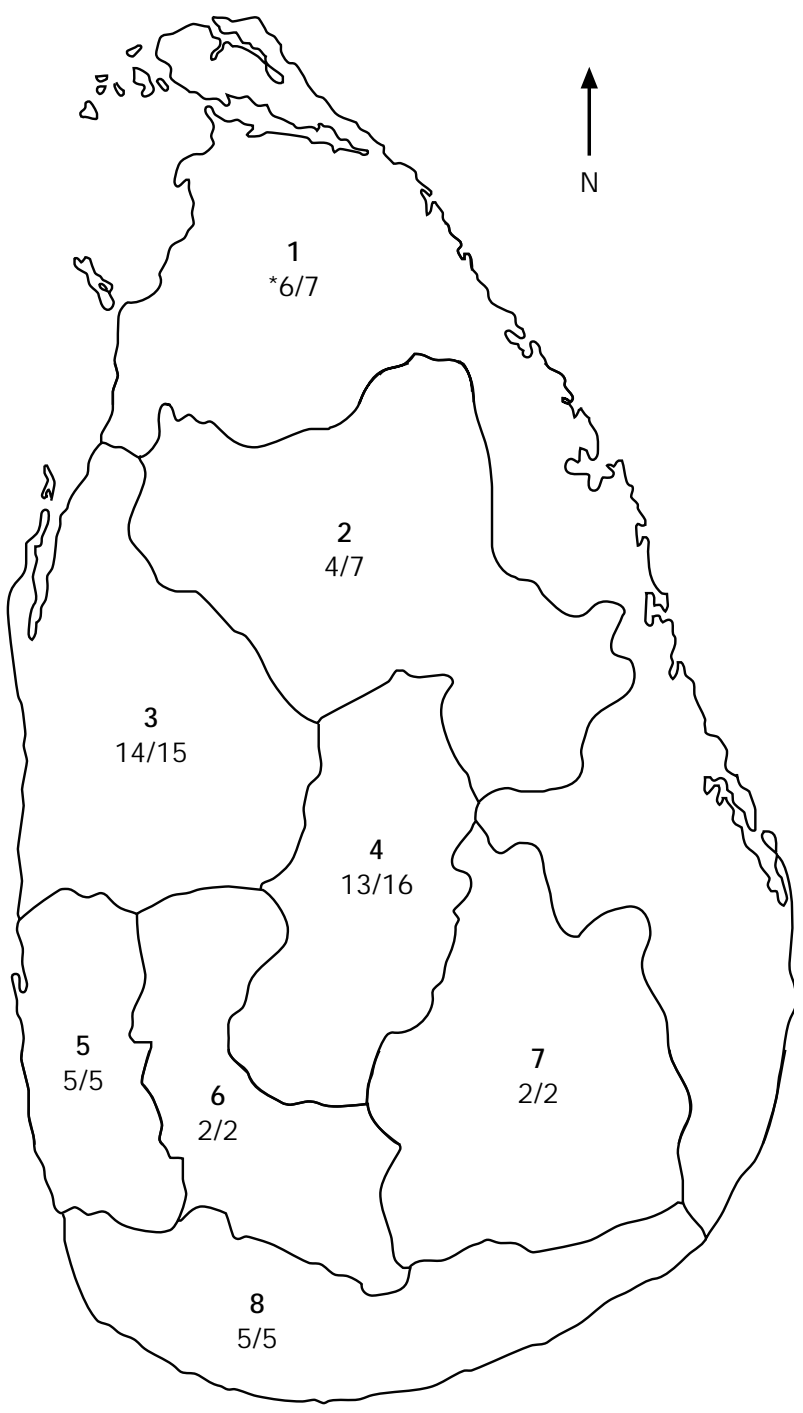

Fig. 2. M ap showing number of DIE codes (numerator)* per number of isolates (denominator) originating from cases of $\mathrm{HS}$ in eight administrative provinces of Sri Lanka: North and East (1), North Central (2), Northwestern (3), Central (4), Western (5), Sabaragamuwa (6), Uva (7) and Southern (8).

than one province; e.g., $\mathrm{B}: 2 / \mathrm{H}$ hal $0018 / \mathrm{H}$ pall 0007 was isolated from elephant (one isolate) and buffalo or cattle (six) and was associated with five of eight provinces. Interestingly, B:2/H hal 0018/H pall 0007 was the DIE code for 21 serotype $B: 2$ P. multocida isolated from a different species in the neighbouring country of India (19 isolates from swine and two from unknown hosts).

\section{Distinction among serotype $B: 3, B: 4$ and $B: 3,4$ isolates}

Twenty-four isolates were identified as serotype $B: 3,4$, four as serotype $B: 3$ and two as serotype $B: 4$. For all of these serogroup $B$ strains, distinction between fingerprint profiles with $\mathrm{Hhal}$ was determined with bands in the 9.78-2.72-kb range, and distinction between fingerprint profiles with $\mathrm{Hpall}$ was determined with bands in the 32.73-4.5-kb range. Bands did not occur

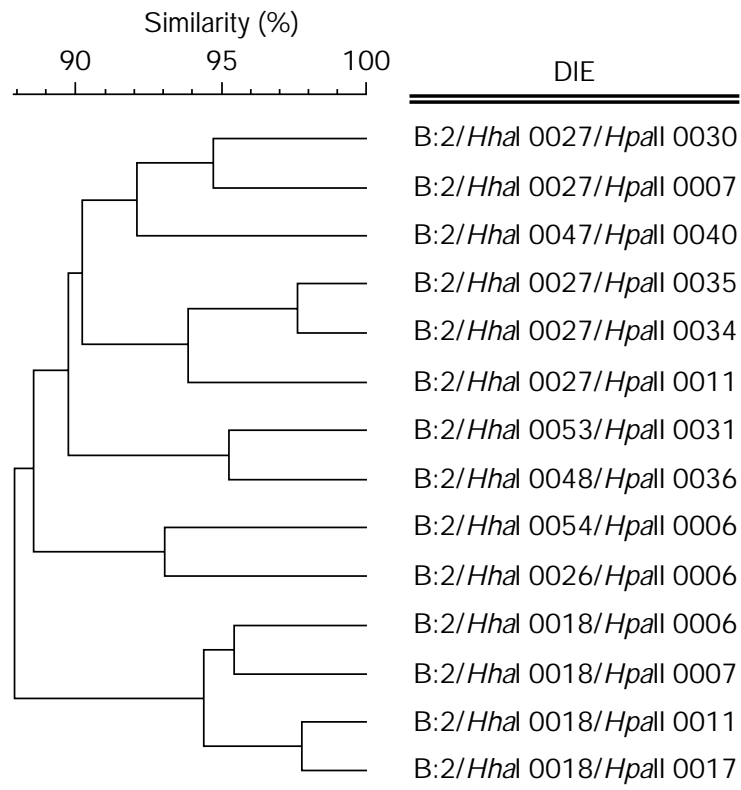

Fig. 3. Dendrogram showing percentage similarity between HS P. multocida isolated in the Northwestern province of Sri Lanka.

above these ranges, and bands were not well separated and defined below these ranges. Fig. 1 shows four of the most frequently observed DNA fingerprint profiles of serotype B:3,4 obtained with $\mathrm{Hhal}$ and Hpall.

Digestion with $\mathrm{Hhal}$ endonuclease resulted in 12 different DNA fingerprint profiles among the serotype $B: 3,4$, two among the $B: 3$ and two among the serotype $B: 4$ isolates. The same DNA fingerprint profile did not occur between isolates of a different serotype. With $\mathrm{Hpall}$ endonuclease, 13 different profiles were found among the serotype $B: 3,4$ isolates, two among the $B: 3$ and two among the serotype $B: 4$ isolates. A gain, the same profile did not occur between isolates of a different serotype.

Except for serotype $B: 3,4$ isolated from fallow deer in Denmark and the UK, isolates that had identical profiles with $\mathrm{Hhal}$ endonuclease also had identical profiles with Hpall. By serology and REA with the two separate endonucleases, 17 DIE code groups were recognised among the 30 isolates that comprised serotypes $B: 3, B: 4$ and $B: 3,4$ (Fig. 4). The similarity between strains with different DIE codes ranged from 57.4 SD $5.9 \%$ to $96.3 \%$. There was no evidence of clustering based upon geographic origin or host species.

Comparisons between DNA fingerprint profiles representing classical HS P. multocida and non-classical HS P. multocida

The DNA of all serotype B:2 isolates (classical HS P. multocida) produced fingerprint profiles characterised by two distinct bands at the top of the gel ( 8.4-7.1 kb) after digestion with $\mathrm{Hhal}$ endonuclease 


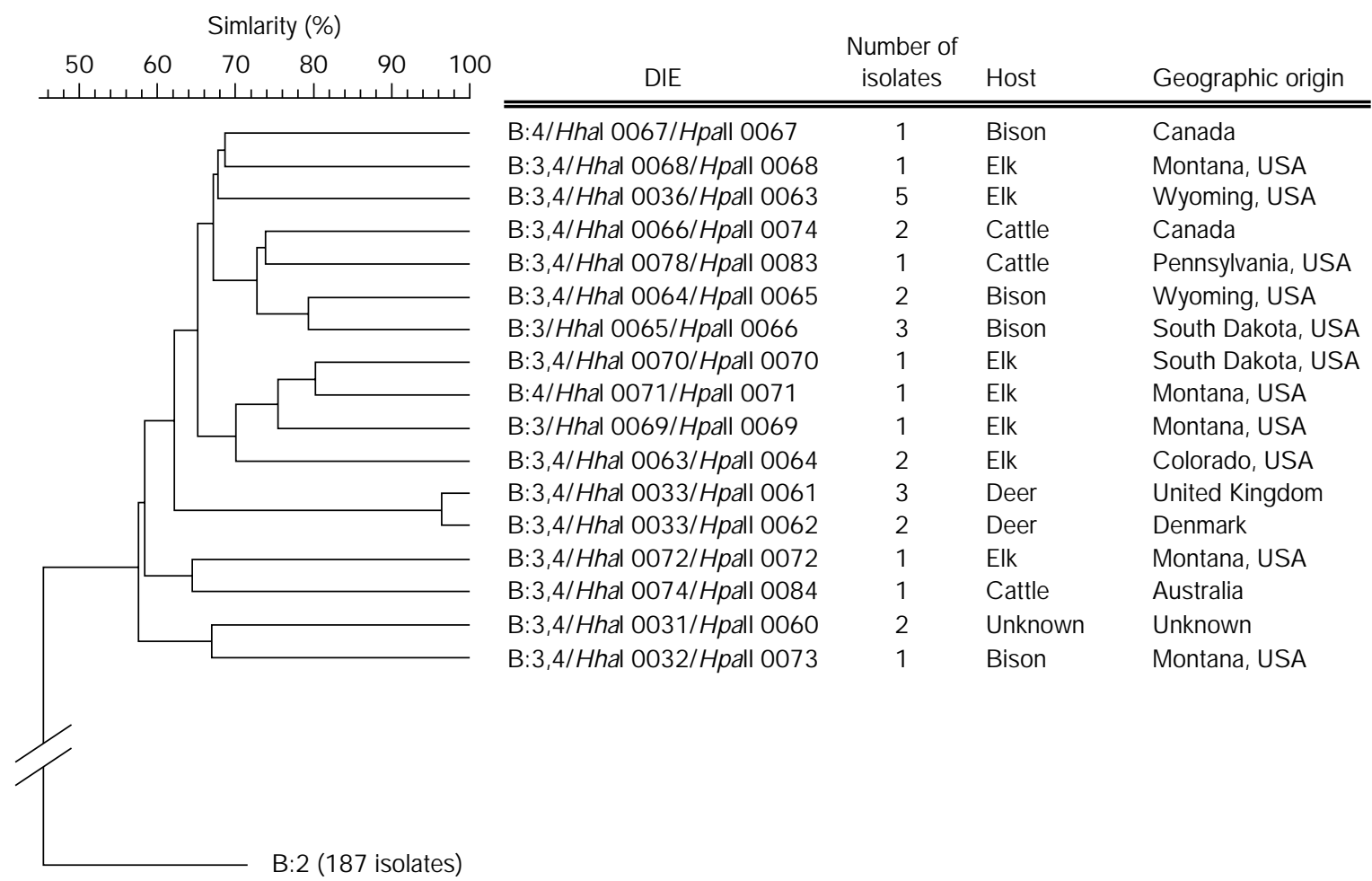

Fig. 4. Dendrogram showing percentage similarity between serotypes $B: 2, B: 3, B: 3,4$ and $B: 4$ P. multocida associated with HS.

and electrophoresis (Fig. 1). Fingerprint profiles with two top bands at this position were not found with $\mathrm{H}$ hal endonuclease for any of the other group $B$ serotypes (B:3, B:3,4 and $B: 4$; non-classical HS P. multocida), and they have not been found with serotypes within groups $A, D, E$ and $F$ of P. multocida (unpublished observations). Except for those isolates whose DNA could not be digested with Hpall, two clusters were seen when all fingerprint profiles of the serogroup B P. multocida were compared (Fig. 4). One cluster consisted of the serotype $B: 2$ isolates; the other cluster consisted of serotypes $B: 3, B: 3,4$ and $B: 4$. Similarity between the two clusters was 45.1 SD $6.5 \%$.

\section{Stability of DNA fingerprint profiles}

Because of the large number of DIE groupings that could be made within the serotype B:2 P. multocida, particularly in countries where HS is endemic (i.e., India and Sri Lanka), it was deemed necessary to determine whether REA fingerprint profiles were relatively stable following laboratory passage of the bacteria. Strain M-1404, the type strain for serotype $B: 2$, has been maintained by the US Department of A griculture as a lyophilised stock culture since 1948. Subcultures have been passaged intermittently by single colony picks on various media for $>50$ years, totalling at least 100 in-vitro passages. When profiles of a single passage of this strain from a stock culture lyophilised in 1948 were compared with the same strain passaged 100 times, there were no differences in fingerprint profiles. Similarly, no differences were seen in fingerprint profiles between one and 30 in-vitro passages of another well-known serotype $B: 2$ isolate, the Insein strain [14].

No influence on DNA fingerprint profiles of $P$. multocida passaged through experimental infection of animals was observed for two serotype $B: 2$ strains. Strain M-1404 re-isolated from the livers of experimentally infected mice did not produce different profiles from the multi-passaged laboratory culture above. Similarly, a Sri Lankan strain (R-39) did not produce different profiles after 10 serial mouse passages.

\section{Discussion}

A previous study showed that REA with $\mathrm{Hhal}$ endonuclease could discriminate among isolates of the serogroup B P. multocida that cause HS [12]. The current study, with a larger number of isolates from more varied sources, showed that REA with two endonucleases ( $\mathrm{Hhal}$ and $\mathrm{Hpall}$ ) could result in better discrimination among these bacteria. Whereas 48 fingerprint profiles were distinguished among 222 isolates with $\mathrm{Hhal}, 88$ different groups (including the isolates that were not digested by $\mathrm{HpalI}$ ) were recognised among the same isolates when the findings with both $\mathrm{Hhal}$ and Hpall were combined. As determined by percentage similarity of the fingerprint profiles, the B:2 serotype constituted a more homogeneous cluster than that seen with the other $\mathrm{HS}$ serotypes tested $(B: 3, B: 4$ and $B: 3,4)$. Particularly interesting was the fact that all serotype $B: 2$ fingerprint 
profiles were characterised by two trailing bands at $\sim 8.4-7.1 \mathrm{~kb}$ after digestion with $\mathrm{Hhal}$ endonuclease and electrophoresis. A profile characterised by these particular bands has not been seen in any other $P$. multocida serotypes treated with the same endonuclease and thus, like the ability to produce hyaluronidase, may constitute another property that can be used as a diagnostic test to recognise members of the B:2 serotype.

Documentation on the host species and geographic origin of the Sri Lankan isolates provided an opportunity to determine the diversity among serotype $B: 2$ that may occur within particular areas of a country where HS is endemic. Although the data show that a large number of genetically different isolates could occur within a specific province (i.e., 14 DIE codes in the Northwestern province), the importance of this finding to the epidemiology of serotype $\mathrm{B}: 2$ and $\mathrm{HS}$ in Sri Lanka is not immediately apparent. However, as a result of this finding, questions arose as to whether serotype $B: 2$ is subject to fingerprint profile change due to either animal or laboratory passage, and whether some strains may be more stable than others. In contrast to the findings reported by Townsend et al. [15], where field alternation gel electrophoresis (FAGE) detected genetic alterations in subcultures of a $\mathrm{N}$ orth American serotype $B: 2$ bison strain (Buffalo $B$ ), the findings reported here indicate that repeated subculture of strain M-1404 (a derivative of Buffalo B also used in that study) did not result in genetic alterations detectable by REA. Furthermore, laboratory passage of the Insein strain and mouse passage of strains M-1404 and R-39 did not result in new and different fingerprint profiles with REA. Laboratory and mouse passages obviously do not represent all the environmental pressures which may initiate genetic changes. Whether transmission of HS P. multocida among the same and diverse natural hosts or immunological pressure from a carrier or vaccinated animal can result in a genetic alteration recognisable by REA remains unknown.

Other molecular methods, including ribotyping and FAGE, have been used to discriminate among $P$. multocida. Comparison between FAGE and ribotyping showed that the former method had greater discriminating power than ribotyping for HS P. multocida [15]. Studies on other P. multocida serotypes where both ribotyping and REA methods were included resulted in better discrimination among strains by $\operatorname{REA}[16,17]$.

REA is a sensitive and relatively uncomplicated method of DNA fingerprinting that directly detects differences between strains of $P$. multocida which appear similar by traditional serotyping methods. Detection of differences with a small number of strains can be accomplished without much difficulty by visual comparison of profiles within a gel. However, as in this study with a large number of strains, computer methods are necessary to simplify gel-to-gel comparisons and storage of reference fingerprint profile images. Images that represent the distinctive $\mathrm{Hhal}$ and $\mathrm{Hpall}$ fingerprints analysed in this study have been archived, forming a reference database that can be used for comparison with images of fingerprints of unknown HS strains. Thus, following methods outlined in this study, it is possible for fingerprint images of HS P. multocida created in another laboratory to be sent electronically (in a tif format) for comparisons.

I thank Ms Gwen E. Nordholm for technical assistance and $\mathrm{Dr}$ Malcolm De Alwis, Veterinary Research Institute, Peradeniya, Sri Lanka, for providing information on the origin of Sri Lankan cultures.

\section{R eferences}

1. Carter GR, De Alwis MCL. Haemorrhagic septicaemia. In: Adlam C, Rutter JM (eds) Pasteurella and pasteurellosis. London, A cademic Press. 1989: 131- 160.

2. De Alwis MCL. Haemorrhagic septicaemia - a general review. $\mathrm{Br}$ Vet J 1992; 148: 99-112.

3. Eriksen L, Aalbaek B, Liefsson PS et al. Outbreaks of haemorrhagic septicaemia in fallow deer (Dama dama) caused by Pasteurella multocida subspecies multocida. J Zoo Wildlife Med 1999; 30: 285-292.

4. Rhoades KR, Rimler RB. Serological characterisation of Pasteurella multocida strains isolated from wild ruminants as capsular serogroup B. Vet Rec 1992; 130: 331- 332.

5. Rimler RB, Rhoades KR, Jones TO. Serological and immunological study of Pasteurella multocida strains that produced septicaemia in fallow deer. Vet Rec 1987; 121: 300-301.

6. Rimler RB, Wilson MA. Re-examination of Pasteurella multocida serotypes that caused haemorrhagic septicaemia in North America. Vet Rec 1994; 134: 256.

7. Wilson MA, Duncan RM, Roffe TJ, Nordholm GE, Berlowski BM. Pasteurellosis in elk (Cervus elaphus): DNA fingerprinting of isolates. Vet Rec 1995; 137: 195-196.

8. Bain RVS, Knox KW. The antigens of Pasteurella multocida type 1. II. Lipopolysaccharides. Immunology 1961; 4: 122129.

9. Rimler RB. Presumptive identification of Pasteurella multocida serogroups $A, D$ and $F$ by capsule depolymerisation with mucopolysaccharidases. Vet Rec 1994; 134: 191-192.

10. Rimler RB, Rhoades KR. Pasteurella multocida. In: Adlam C, Rutter JM (eds) Pasteurella and pasteurellosis. London, Academic Press. 1989: 37-73.

11. Rimler RB, Rhoades KR. Hyaluronidase and chondroitinase activity of Pasteurella multocida serotype $B: 2$ involved in haemorrhagic septicaemia. Vet Rec 1994; 134: 67-68.

12. Wilson MA, Rimler RB, Hoffman LJ. Comparison of DNA fingerprints and somatic serotypes of serogroup $B$ and $E$ Pasteurella multocida isolates. J Clin Microbiol 1992; 30: 1518- 1524.

13. Rimler RB, Brogden KA. Pasteurella multocida isolated from rabbits and swine: serologic types and toxin production. Am J Vet Res 1986; 47: 730-737.

14. Knox KW, Bain RVS. The antigens of Pasteurella multocida type 1. I. Capsular polysaccharides. Immunology 1960; 3: 352- 362.

15. Townsend KM, Dawkins HJ, Papadimitriou JM. A nalysis of haemorrhagic septicaemia-causing isolates of Pasteurella multocida by ribotyping and field alternation gel electrophoresis (FAGE). Vet Microbiol 1997; 57: 383-395.

16. Gardner IA, Kasten R, Eamens GJ, Snipes KP, Anderson RJ. Molecular fingerprinting of Pasteurella multocida associated with progressive atrophic rhinitis in swine herds. J Vet Diagn Invest 1994; 4: 442-447.

17. Zhao G, Pijoan C, Murtaugh MP, Molitor TW. Use of restriction endonuclease analysis and ribotyping to study epidemiology of Pasteurella multocida in closed swine herds. Infect Immun 1992; 60: 1401-1405. 